\title{
Dante, el más Grande Poeta de la Cristiandad en la Obra
} de Julio Picasso

Eduardo Ponce North*

Universidad Católica Sedes Sapientiae eduardoponcen@gmail.com

Resumen: Este artículo fue escrito como un homenaje al profesor Julio Picasso Muñoz, quien dejó este mundo en enero del 2015, y por los 750 ańos de nacimiento del poeta Dante Alighieri. Para realizar este trabajo fue necesario revisar las obras de traducción de libros clásicos, realizados por Julio Picasso, y más precisamente, las introducciones de dichas traducciones donde resalta siempre un comentario alusivo o la referencia a alguna obra del poeta de la Divina Comedia. Con este recorrido se pretende demostrar la influencia que el latinista ha recibido del poeta escatológico. Por esa razón, se revisarán las siguientes traducciones: La amistad, de Cicerón; Tratado de Música, de Boecio; La naturaleza. De rerum natura, de Lucrecio y la Antología latina, todas realizadas por Julio Picasso. Además, se revisarán dos artículos escritos por él en donde sale a relucir siempre su amor por la obra de Dante como "Dante y la leyenda de Silvestre y Constantino" y "Sic notus Ulixes?".

Palabras clave: Homenaje, literatura, latín, poeta, alegoría, profesor.

\section{Dante, the Greatest Poet of Christendom in the Work of}

\section{Julio Picasso}

\begin{abstract}
This article was written as an homage to professor Julio Picasso Munoz who left this world in January 2015 and for 750 years of the birth of the poet Dante Alighieri. To do this job was necessary to check the works of translation of classic books done by Julio Picasso and mostly the introduction to the texts where it always highlights an elusive comment or a reference to any of the works of the poet of the Divina Comedia. With this review we pretend to show the influence received from the poet. We will review the translation of Cicero's La Amistad, Boecio's Tratado de Musica,

Eduardo Ponce North es profesor en Filosofía y Religión por la Universidad Católica Sedes Sapientiae. Dicta clases de Filosofía Personalista en el Diplomado Persona y Familia en la Facultad de Teología Redemptoris Mater. Recientemente, ha participado como ponente en la Mesa redonda: “Ciencia y Fe: ¿̇un encuentro posible?”. Asimismo, ha publicado diversos artículos de índole educativa en revistas especializadas.
\end{abstract}


Lucrecio's De rerum natura, and Julio Picasso's Antologia Latina, besides two written articles where it always show his love for Dante's works like in "Dante y la leyenda de Silvestre y Constantino" and "Sic notus Ulixes?". Lastly we will show the influence the professor received through his job from the classic poet.

Keywords: Homage, literature, poet, allegory, professor, Dante Alighieri.

\section{Un Breve Recorrido por el Mundo de Dante desde la Perspectiva de Julio Picasso}

ste texto es un homenaje al poeta Dante Alighieri, ${ }^{1}$ que nació hace 750 años; junto
con él recordamos también a nuestro profesor, humanista, políglota y amigo Julio Picasso Muñoz, quien nos dejó y pasó al Padre el 30 de enero del 2015. Julio destacó ampliamente como especialista en lenguas clásicas, de manera especial con el latín, griego y hebreo. Fue formado en sus estudios primarios y secundarios con los salesianos. Luego, estudió ingeniería agrónoma en la Universidad Nacional Agraria y reforzó sus estudios en la Universidad de la Sorbona en París. Asimismo, fue miembro de la Dante Society of America (Universidad de Harvard), del Instituto Riva-Agüero (PUCP), de la Sociedad Hispánica de Estudios Neogriegos (Granada, España). Por último, llegó a ser miembro fundador de la Sociedad Peruana de Estudios Clásicos.

Como podrá apreciarse en las siguientes páginas, el profesor Picasso fue un estudioso de la obra del poeta florentino. En su basta biblioteca podían encontrarse los libros de Dante en su idioma original y numerosos volúmenes de crítica sobre estos. Producto de dicho amor, sobre todo a la Divina Comedia, dedicó parte de su tiempo a la lectura y estudio de la obra dantesca. Esto lo ha llevado a escribir sendos artículos eruditos sobre la obra de Dante Alighieri que mencionaré a continuación: "Dante y la leyenda de Silvestre y Constantino" y "Sic notus Ulixes?".

De igual modo, parte de esta pasión por las obras de Dante se ve reflejada en su trabajo como traductor. En las introducciones de sus libros vemos referencias a la Divina Comedia o a alguna otra obra del poeta florentino. Esta influencia no solamente se mostraba en sus trabajos, sino también en sus clases y también en las tertulias.

1 Para las obras de Dante, se usarán las siguientes abreviaturas: If (Inferno), Pg (Purgatorio), Pd (Paradiso) y Cv (Convivio). 
Ya que este artículo se trata de un homenaje a uno de esos profesores de lujo que el destino o la gracia pone en tu camino y al gran poeta escatológico, la única forma de poder hacer un trabajo que tribute a ambos fue sumergirse en los trabajos del didáscalo Picasso. Hubo que revisar todos los artículos, traducciones y presentaciones hechas por él. Fue una labor placentera poder hacer un recorrido por todos esos libros y explorar los prefacios de sus traducciones, simbolizó un retorno a las aulas y volver a escucharlo hablar de aquello que le apasionaba. Más aún, enorme llegó a ser mi sorpresa al encontrar, en este camino, referencias a la obra de Dante en la gran mayoría de los prólogos de sus libros.

Prontamente tracé diferentes hipótesis al respecto: (a) Julio Picasso había usado la obra de Dante para escoger los libros que iba a traducir, (b) era obra del azar que esto pasara, y, por último, (c) la tercera hipótesis (la más verosímil) apuntaba a que los libros que escogía para trabajar no necesariamente lo hacía por estar ligados a la obra de Alighieri, sino que el profesor los escogía a priori por una motivación educacional. Luego, los relacionaba con Dante al momento de hacer sus trabajos de ubicación del lector en un prólogo de una obra clásica y medieval. Aunque definitivamente se puede notar la influencia de la obra dantesca en su trabajo como traductor, dicho rasgo se esclarecerá a lo largo del texto.

\section{Dante y los Trabajos de Traducción de Julio Picasso}

$\mathrm{E}_{\mathrm{n}}^{\mathrm{n}}$ la traducción del libro La amistad, de Cicerón, Julio Picasso muestra a un Dante más humano. Precisamente en su prefacio, al hablar de la influencia de este diálogo en el poeta, observa lo siguiente:

En efecto para Dante; el amor subliminado en el recuerdo de Beatriz no es sino una idea trasferida de Lelio. Lo mismo ocurre con el tema del capítulo XVIII de La Vida Nueva: el amor tiene en sí mismo su premio. Aún más; la predilección de Dante por su lengua romance tiene sus motivaciones en el diálogo ciceroniano (De am.; V 19 Y Cv; I; XII; 3 ss.). (Picasso, 1997, p. 71)

En este paratexto nos enseña que el poeta tuvo una predilección por la lectura de Cicerón. Esto se debe a que cita en sus libros cuatro obras de Marco Tulio: Sobre los deberes, Sobre los términos extremos, Sobre la vejez y Sobre la amistad. Para resaltar la importancia de 
estas lecturas se menciona, además, que en la Edad Media los intelectuales solo conocieron los dos últimos diálogos.

Por otro lado, el poeta florentino también leyó al humanista san Severino Boecio mientras buscaba consuelo en su obra. Como él mismo lo dice y trascribimos a continuación:

Después de cierto tiempo; mi mente se esforzaba por sanar; se propuso ya que ni mis propios medios ni los ajenos podían consolarla— retornar al método que ciertos desconsolados usaron para consolarse; y me puse a leer aquel libro de Boecio (La consolación de la filosofía). (Cv. II; XII 3 ss)

[En el mismo tratado vemos la importancia que estas lecturas representaron para él] Boecio y Tulio; con la dulzura de sus palabras; me condujeron al amor; es decir al estudio de la filosofía. (Cv, II, XV)

Dante, siglos antes de ser autorizado el culto como santo a san Severino por el papa León XIII, puso a Boecio en el paraíso. Julio Picasso toma esto en cuenta en la presentación a la traducción del Tratado de música:

Incluye a Boecio en el Cielo de los Espíritus Sabios (Paraíso, XIII). Boecio, para Dante, hace el contrapeso a las enseñanzas de Brunetto Latino. Este le había enseñado "cómo se eterniza el hombre (If XV, 85) adquiriendo fama en el mundo. Boecio, en cambio, fue el maestro de la trascendencia: él manifiesta la falacia del mundo”. (2012, p. XVI)

De igual modo, puede mencionarse el libro Antología latina, escrito por Picasso. En este, al hablar sobre la vigencia del latín, afirma lo siguiente:

Si bien nuestras lenguas romances empezaron a hablarse en el siglo VII de nuestra era; no por eso la gente culta dejó de hablar y escribir en latín. La Divina Comedia, el Cántico Espiritual y el Discurso del Método tuvieron que traducirse al latín para que pudieran ser entendidos por el mundo. (1995, p. 4) 
Todo lo anterior nos demuestra la importancia de la Divina Comedia en esta época y cómo el profesor Picasso tuvo siempre presente a Dante en su discurso. Además, con esta antología recalca la importancia del estudio del latín por ser una de las lenguas más precisas que se conocen y nos ayuda a acercarnos más a los clásicos para su lectura y estudio. Él siempre nos decía en clase que este idioma seguía vivo por ser la lengua oficial del Vaticano, ya que a partir del año 370 se estableció como lengua litúrgica y oficial. Más aún, hoy en día se le sigue estudiando en las universidades y facultades de teología.

A su vez, para él era necesario el estudio del latín principalmente en favor de nosotros mismos, puesto que es una lengua formativa. A través de ese consejo, quiso dejar en claro que esta lengua nos puede ayudar a hablar correcta y sintéticamente el propio idioma. Demás está decir que nos ayuda a expresarnos de forma clara.

Personalmente, este idioma fue el que más le costó aprender, a pesar de haberlo estudiado desde los siete años de edad. Esto lo dio a conocer en una entrevista para el diario $E l$ Comercio. Al preguntársele sobre cuál había sido el idioma que le atrajo mayores complicaciones, dijo: "El latín es la lengua que entraña más dificultad. Pero mi facilidad para aprender idiomas vino justamente del dominio del latín, que es la madre de todas las lenguas romances" (Sanz, 2012, párr. 16).

\section{Dos Artículos Dedicados a la Divina Comedia}

\section{1 "Sic notus Ulixes?"}

En el artículo "Sic notus Ulixes?" publicado en la revista Cuadernos Literarios N. 8 del Fondo Editorial UCSS, nuestro insigne maestro nos hace un recorrido sobre la aparición de Ulises en la Eneida, de Virgilio y en la Divina Comedia, de Dante. Empieza el artículo con un cuestionamiento sobre el Ulises dantiano. Sabemos que todas las referencias del personaje Ulises le llegaron al poeta florentino solo por los romanos y en especial por Virgilio con la Eneida.

Pero el genio de Dante logró fabricar con Ulises una de las páginas más importantes de la literatura universal: cincuenta y dos versos que han hecho y hacen emocionar a sus lectores de todo el mundo durante más de siete siglos. Pero hasta ahora subsiste la duda de si leemos como se debe estos magníficos 
versos. ¿Conocemos al Ulises dantiano? Sic notus Ulixes?, como nos gritaría Laoconte. (Picasso, 2009, p. 160)

Estamos al corriente de que Ulises, en la Divina Comedia, aparece en If XXVI, precisamente en la bolsa octava de los consejeros de fraude y dentro, además, del círculo octavo de los fraudulentos en donde cada condenado está encerrado o envuelto en llamas. En dicho lugar está presente su compañero Diómedes, quien lo acompañó en la guerra de Troya y que juntos llevaron a cabo con éxito una serie de empresas que requerían astucia y engaño. En el análisis de estos versos, Julio Picasso nos habla de la forma de leer este pasaje:

Dante requiere varias lecturas. En la primera el lector debe aplicar sus sentidos para apreciar la versificación, los encabalgamientos, las figuras retóricas: aliteraciones, metáforas, alusiones, el verdadero sentido de las palabras y las reminiscencias clásicas a fin de hacer sobresalir la originalidad de Dante. En este pasaje lo primero que notamos es la elevación de estilo, propio de la épica. El uso de la primera persona plural le da un tinte más solemne y patético. Sin embargo, muy pronto (If XXVII, 21) nos enteramos de que Virgilio se despide de Ulises con una chocante despectiva frase dialectal: Istra ten va, più non t'adizzo [Ahora vete de aquí, ya no te estimulo a hablar]. (Picasso, 2009, p. 163)

Cerrando el artículo, el profesor nos lleva a una reflexión sobre el Paraíso cuando Dante es guiado por Beatriz y esta le dice que mire a la tierra y al observar el mar Atlántico lo señala como "la loca ruta de Ulises" (Picasso, 2009, p.163). En esta escena, Julio nos acerca a un significado que podría pasar desapercibido para el lector novel. De ese modo, Dante habla en un lenguaje alegórico para poder mostrar su doctrina:

Lo que Ulises buscó con su viaje fue arribar a la montaña del Purgatorio, es decir, a la salvación, con su propio esfuerzo y con sus propios medios. No tomó en cuenta que la salvación es más cuestión de gracia divina que de esfuerzo humano. El alma se salva per sola grazia, non per esser degna (Pd. XII, 42): únicamente por gracia de Dios, no por ser digna. El cristiano que piensa al revés cae inevitablemente en el pelagianismo, herejía ya combatida con brío por san Agustín. (Picasso, 2009, p. 163) 
Con esta cita nos acercamos también a la persona preocupada y entendida en doctrina como lo fue Dante. Julio Picasso, al igual que el maestro florentino, procuró siempre estar bien informado de la doctrina y conocerla a fondo. Personalmente, vi cómo procuraba leer las epístolas publicadas por Benedicto XVI en cuanto eran publicadas.

\section{2 "Dante y la leyenda de Silvestre y Constantino"}

El artículo "Dante y la leyenda de Silvestre y Constantino", apareció en el BIRA (Boletín del Instituto Riva Agüero). En este texto, nuestro recordado educador tuvo como motivo mostrar la leyenda del papa san Silvestre y el emperador romano Constantino para acercarnos y entender con mayor claridad algunos pasajes relacionados a estos personajes en la Divina Comedia. Así, el profesor nos explica que dicha leyenda es una invención que no cuenta con valor histórico. En seguida, al ver que en latín se dice actus, y más detalladamente Actus Siluestri, precisa lo siguiente: "por el 440, un clérigo (o grupo de clérigos) del titulus compuso los Actus Silvestri. Con la manifiesta intención de realzar su iglesia con un mayor prestigio asociándole el recuerdo del papa” (Picasso, 1997, p. 431).

Según esta leyenda, el papa san Silvestre vivió en un titulos o casa para sacerdotes fundada por el ciudadano Equicio durante el siglo III en Roma. Luego, la fama de esta leyenda fue creciendo al punto que, siglos después, el papa Símaco, dedicó a su antecesor la sala litúrgica de la casa y colocó allí una representación del venerable. Pasado el tiempo, entre fines del siglo VI y comienzos del IX, se termina de escribir este actus relatando la muerte de san Silvestre.

Asimismo, en esta leyenda se cuenta que los cristianos eran perseguidos y Constantino, por su parte, colaboró en favor de dichos actos. A consecuencia de esto, como castigo divino, contrajo la lepra. Después, se cuenta de su arrepentimiento y conversión; al ser bautizado por san Silvestre se cura de este mal. Seguidamente, en el actus se relata la entrega de un donativo al Papa por intermedio de un documento privado donde Constantino le dona toda la Europa Occidental.

Julio Picasso hace gala de su erudición y nos presenta un cuadro completo de la leyenda del papa san Silvestre. Para ello, investiga cuidadosamente cada punto con la finalidad de que el lector cuente con el conocimiento necesario para entender a cabalidad el mensaje de la Divina Comedia. Desarrolla estos personajes por su importancia en ese texto y por su valor alegórico; sabemos que Constantino es nombrado siete veces, al comienzo, en If, precisamente en la bolsa de los simoniacos perteneciente al último círculo de los fraudulentos. 
Posteriormente se le menciona en la octava bolsa de los consejeros fraudulentos. Lo encontramos también en el Pg XVI de los iracundos y en el Paraíso Terrenal (Pg. XXVIIIXXXIII). También en el segundo Cielo y en el sexto Cielo. En estos pasajes la leyenda de san Silvestre y Constantino es nombrado incidentalmente, exprofeso o de forma alegórica. A modo de ejemplo, mencionaremos estos pasajes:
Después que Constantino hubo llevado el águila
en contra del movimiento del sol, movimiento que ella siguió
detrás del antiguo héroe, que tomó a Lavina como esposa,
por más de doscientos años el ave de Dios
se mantuvo en los límites de Europa,
cerca de los montes de donde salió primero.

(Pd. VI, 1-6)

Las alusiones a dicha leyenda continúan en pasajes posteriores. Esto Lo podemos apreciar en los siguientes versos:

El otro que sigue, con buena intención

que dio mal fruto, para ceder al pastor,

se hizo griego con las leyes conmigo;

conoce, pues, ahora cómo el mal derivado

de su buen obrar no le es nocivo

aunque por ello el mundo esté destruido.

(Pd. XX, 55- 56)

Estos artículos nos muestran la sutileza del maestro Julio Picasso para captar el sentido correcto del poema escatológico, es producto de años de estudio y dedicación a la obra de Dante, de la que solía recitar pasajes de memoria. Dado el carácter pedagógico y como base para futuras investigaciones, nos deja un legado que debe ser revisado, estudiado, por los estudiantes y docentes interesados en profundizar sus conocimientos en la obra de Dante. 


\section{La Importancia del Estudio de los Clásicos}

$\int$ ulio Picasso compartía, junto con la Universidad Católica Sedes Sapientiae, la política de traducir y rescatar a los clásicos tanto cristianos como paganos. Su intención con esta labor fue la de poder ayudar a los alumnos en su desarrollo estudiantil y, sobre todo, humano. Sin embargo, el quehacer de traducción se le dificultaba en muchas ocasiones. Esto se debía a la falta de textos críticos y fuentes bibliográficas fiables. Pero, gracias al trabajo de investigación y al dominio de seis idiomas — más aún, como él decía, gracias a su ángel guardián—, así como a su gran amigo André Schmitt, lograba encontrar los textos idóneos para empezar su tarea. Esto sucedió, por ejemplo, con la traducción del libro Los deberes. Los himnos, de san Ambrosio, el cual fue por primera vez traducido al castellano.

En su labor como docente investigador, el profesor legó a la universidad la traducción de la obra integra de Virgilio, como él lo llamaba, el escritor más importante del occidente. Esta se compuso por las Bucólicas y Geórgicas, y la Eneida. También tradujo para esta institución El Maestro, de santo Tomás, de suma importancia para su Facultad de Ciencias de la Educación y Humanidades.

Del mismo modo, solía decir a sus alumnos que su mayor aventura era la traducción, pues debía meterse en la mentalidad de un autor de hace veinte siglos y conocerlo a fondo. Afirmaba: "Tengo que convertirme en Virgilio para traducir la Eneida", es decir, tenía que ser otro Virgilio porque su traducción debía ser fidedigna. Asimismo, para él era casi tan importante como la traducción, la notación del libro y la introducción, con la finalidad de tener una herramienta que logre una mayor comprensión al momento de leer cualquiera de sus trabajos: "un clásico no es un autor contemporáneo, requiere que el traductor coloque al lector en la época. Para eso se necesitan notas, introducción, láminas y mapas" (Sanz, 2012, párr. 8).

Esta aventura empezó cuando vivía en Francia y reforzó su estudio del latín en la Sorbona con la guía de nada menos que Pierre Grimal. Así, sus trabajos de traducción comenzaron en el año 1985 con El Satiricón, de Petronio, publicado en España por Ediciones Cátedra. Para los que quieran indagar un poco más en la labor del profesor Picasso como traductor y sus trabajos académicos se ha elaborado un listado con sus obras:

- Petronio: El Satiricón (Barcelona, España, Cátedra, 1985). 
- Picasso: Latín niveles I, II, III, IV (Lima, Fondo de la Facultad de Teología Pontificia y Civil de Lima, 1992).

- Picasso: Las preposiciones griegas en el NT. (Lima, Fondo de la Facultad de Teología Pontificia y Civil de Lima, 1994).

- Anónimo: Himno Acázistos' ala Virgen (Revista del Arzobispado de Lima, 1994).

- Picasso: Antología latina. (Lima, Fondo de la Facultad de Teología Pontificia y Civil de Lima, 1995).

- Cicerón: La amistad (Lima, Grambs, 2000).

- Boecio: Cinco opúsculos teológicos (Lima, PUCP, 2002).

- Virgilio: Bucólicas y Geórgicas (Lima, Fondo Editorial UCSS, 2004).

- Horacio: Artepoética (Epistola a los Pisones) (Lima, Fondo Editorial UCSS, 2006).

- Virgilio: La Eneida (Lima, Fondo Editorial UCSS, 2007).

- Santo Tomás de Aquino: El maestro (Lima, Fondo Editorial UCSS, 2008).

- Longo: Dafnis y Cloe (Lima, PUCP, 2008).

- San Ambrosio: Los deberes. Los himnos. (Lima, Fondo Editorial UCSS, 2009).

- Catálogo de la muestra Galileo, mito y realidad (Lima, Fondo Editorial UCSS, 2009).

- Plutarco/San Basilio: Cómo el joven debe leer los poemas / A los jóvenes sobre la manera desacarprovecho de la literatura griega (Lima, Fondo Editorial UCSS, 2010).

- Anónimo: Ellibrodelamanzana o De la muerte de Aristóteles y Prólogo de Manfredo, principe de Tárento (Lima, Fondo Editorial UCSS, 2011).

- Boecio: Tratado de música (Lima, Fondo Editorial UCSS, 2012).

- Lucrecio: La naturaleza. De rerum natura (Lima, Fondo Editorial UCSS, 2013).

- Pedro de Villagómez: Semblanza poética de Sto. Toribio (Revista de Teología, 2013).

- Estacio: La Tebaida (próxima publicación, Fondo Editorial UCSS).

El profesor Picasso fue, ante todo, un humanista. Por esa misma razón, emulando al latino Terencio, llegó a afirmar: "soy hombre y nada de lo humano me es extraño" (Sanz, 2012, párr. 2). Como vemos por el listado de sus libros ordenados por fechas de publicación, llevó a cabo un trabajo de rescate de lo clásico, de los humanistas que lo precedieron. 
Para él, lo clásico era lo nuevo, lo que nunca pasaba de moda, su importancia radicaba en lo actual de estos escritos. Al respecto, Umberto Eco, en una conferencia dictada en la Universidad de Berkeley en el año 1994, nos indica que:

La lectura de los clásicos es siempre fundamental, porque nuestro modo de pensar ha sido determinado por ellos. Es el secreto del retorno a los orígenes: para entender por qué pensamos las cosas de este modo. Por eso, yo no acepto algunas tendencias de Estados Unidos que pretenden destruir este canal. Si se es negro — dicen—, no hay que estudiar a Shakespeare. No: si uno es africano, debe estudiar también las tradiciones africanas. Pero hay que estudiar además a Shakespeare, porque si se nace en Norteamérica, el modo de pensar está determinado por Shakespeare. Hay que descubrir eso y el porqué. Ese es el punto. La lectura de los clásicos es el eterno retorno al vientre materno. Es lo mínimo con lo que hay que empezar. (Citado en Peirano, 1994, párr. 2)

El profesor Picasso siempre comentaba en clase que nosotros: "pensábamos como griegos y hablábamos como latinos", porque nuestro pensamiento estaba cimentado en las bases de la filosofía y cultura griega, y nuestro idioma tiene su base en el latín. Esta frase siempre lo llevaba a hablar de los clásicos greco-latinos en clase. Como alumnos, nos invitaba a participar de ese banquete que era la lectura de los clásicos, desde Homero, pasando por Virgilio, Ovidio, Cicerón, Lucrecio, Dante, entre otros. Siempre con su guía y consejo, atendiendo a las dudas que pudieran surgir.

\section{Conclusiones}

$\mathrm{E}$ n este artículo se pretendió dar a conocer, para los no iniciados, el legado del profesor CPicasso, en sus trabajos de traducción, las introducciones de sus libros, los diferentes artículos eruditos y su carrera como profesor. Sabemos que nuestro docente tuvo una formación humanística desde temprana edad con los salesianos en Magdalena. Su amor por las letras y por el saber vinieron incentivados de este centro de formación, allí aprendió latín e italiano, la filosofía y el amor a los estudios.

Gracias a estos saberes, que él supo aprovechar, nos ha heredado a todos parte de estos conocimientos junto con la alegría salesiana: cuando nos encontrábamos en el aula 
de clases o, mejor aún, en aquel lugar donde uno podía viajar y volar alto con la lectura de grandes obras clásicas. Vemos en toda su obra este legado por el conocimiento, por lo clásico, por lo humano, por aquello que se está perdiendo y que nuestro profesor hizo todo lo posible por conservar y, muchas veces, rescatar del olvido. Quiso traerlo a nuestro idioma con un lenguaje sencillo, sobrio, sin caer en exageraciones del lenguaje, muy por el contrario, nos mostraba que desde la simpleza se puede lograr algo bello.

He recorrido junto con ustedes una serie de obras de Julio Picasso Muñoz. En esta se ha podido ver a modo de lista o menú (como diría nuestro profesor Andrés Aziani) todos los artículos y referencias a Dante Alighieri. De igual manera, espero que este texto abra su apetito por saber más y escojan la producción del profesor Picasso, la cual siempre será útil para alimentar su intelecto. 


\section{Referencias}

Boecio. (2012). Tratado de música (Trad. J. Picasso Muñoz). Lima, Perú: Fondo Editorial UCSS.

Cicerón. (2000). La amistad (Trad. J. Picasso Muñoz). Lima, Perú: Grambs.

Dante Alighieri. (2005). Convivio (Ed. \& Trad. F. Molina). Madrid, España: Cátedra.

Lucrecio. (2013). La naturaleza. De rerum natura (Trad. J. Picasso Muñoz). Lima, Perú: Fondo Editorial UCSS.

Peirano, L. (julio, 1994). La importancia de leer los clásicos. Aceprensa. Recuperado de https://www.aceprensa.com/articles/la-importancia-de-leer-a-los-cl-sicos/

Picasso, J. (1995). Antología latina. Lima, Perú: Facultad de Teología Pontificia y Civil de Lima.

Picasso, J. (1997). Dante y la leyenda de Silvestre y Constantino. Boletín del Instituto RivaAgüero, 24, 431- 442.

Picasso, J. (2009). Sic notus Ulisex? Cuadernos Literarios, (8), 157-165.

Sanz, F. (30 de julio de 2012). No creo que mis libros sean 'best sellers', pero tarde o temprano seré reconocido. El Comercio, p. A20. 